\title{
Krankenversicherung mit INTRAS
}

\author{
Profitieren Sie vom FMH Insurance Services Kollektivvertrag
}

\section{FMH Insurance Services Kollektivvertrag}

Treten Sie dem FMH Insurance Services Kollektivvertrag bei, der mit der INTRAS abgeschlossen wurde. Profitieren Sie und Ihre im gleichen Haushalt lebenden Familienmitglieder und Konkubinatspartner von den Topleistungen und den attraktiven Prämienrabatten.

\section{Ihre Vorteile auf einen Blick}

\section{Einfrieren des Eintrittsalters}

Normalerweise erhöhen sich die Prämien der Zusatzversicherungen, wenn die versicherten Personen älter werden. Bei der INTRAS wird zur Prämienberechnung ab Alter 26 immer das Eintrittsalter berücksichtigt. Bleiben Sie der Kasse treu, profitieren Sie langfristig von tieferen Prämien.

\section{Zusatzversicherung für ambulante Leistungen - bis zu 30\% Rabatt}

Durch den FMH Insurance Services Kollektivvertrag kommen Sie bei den Zusatzversicherungen für ambulante Leistungen UNO+ oder DUE+ in den Genuss eines Sonderrabatts von bis zu 30\% der normalen Prämie.

Spitalzusatzversicherung - bis zu $40 \%$ Rabatt

Weiter erhalten Sie auf den Spitalzusatzversicherungen OPTIMA+ und QUADRA+ (halbprivat oder privat) ebenfalls einen Rabatt von bis zu $40 \%$ der normalen Prämie.

Sind Sie bereits bei der INTRAS versichert? Bis Alter 65 können Sie ganz einfach und ohne grossen Aufwand dem FMH Insurance Services Kollektivvertrag beitreten. Rufen Sie uns an, damit auch Sie in Zukunft von günstigeren Konditionen profitieren können.

\section{Profitieren Sie von unserem Angebot}

Nutzen Sie die Vorteile des FMH Insurance Services Kollektivvertrags und bestellen Sie noch heute Ihre persönliche Offerte mit dem untenstehenden Antworttalon (bitte eine aktuelle Policenkopie beilegen).

\section{Antworttalon}

Vorname / Name

Adresse

PLZ / Ort

Geburtsdatum

Telefon privat/Geschäft

Beste Zeit für einen Anruf

E-Mail-Adresse

O Bitte senden Sie mir eine Offerte. (Bitte eine aktuelle Policenkopie beilegen!)

Ich wünsche eine persönliche Beratung. Bitte rufen Sie mich an.

Ich interessiere mich für folgende Produkte:

$\begin{array}{ll}\text { Todesfallversicherung } & \text { Pensionskasse BVG } \\ \text { Säule } 3 a & \bigcirc \text { Rechtsschutzversicherung } \\ \text { Finanz-/Steuerplanung } & \bigcirc \text { Berufshaftpflichtversicherung } \\ & \end{array}$

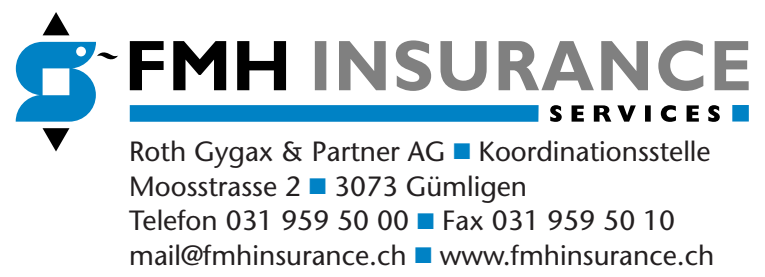

